\title{
Do We Need to Design Course-Based Undergraduate Research Experiences for Authenticity?
}

Susan Rowland, * Rhianna Pedwell, Gwen Lawrie, Joseph Lovie-Toon, and Yu Hung School of Chemistry and Molecular Biosciences, University of Queensland, St. Lucia, Queensland 4072, Australia

\begin{abstract}
The recent push for more authentic teaching and learning in science, technology, engineering, and mathematics indicates a shared agreement that undergraduates require greater exposure to professional practices. There is considerable variation, however, in how "authentic" science education is defined. In this paper we present our definition of authenticity as it applies to an "authentic" large-scale undergraduate research experience (ALURE); we also look to the literature and the student voice for alternate perceptions around this concept. A metareview of science education literature confirmed the inconsistency in definitions and application of the notion of authentic science education. An exploration of how authenticity was explained in 604 reflections from ALURE and traditional laboratory students revealed contrasting and surprising notions and experiences of authenticity. We consider the student experience in terms of alignment with 1) the intent of our designed curriculum and 2) the literature definitions of authentic science education. These findings contribute to the conversation surrounding authenticity in science education. They suggest two things: 1) educational experiences can have significant authenticity for the participants, even when there is no purposeful design for authentic practice, and 2) the continuing discussion of and design for authenticity in UREs may be redundant.
\end{abstract}

\section{INTRODUCTION}

The current landscape of science, technology, engineering, and mathematics (STEM) education reform promotes the ideal of undergraduates engaged in teaching and learning experiences that present accurate representations of what STEM professionals do in the "real world" (Brownell and Kloser, 2015). The greatest movement toward this ideal has arguably occurred within the last 5 years, with the rapid spread of course-based undergraduate research experiences, or CUREs (Auchincloss et al., 2014; Brownell and Kloser, 2015; Linn et al., 2015). Drawing from the success of the apprenticeship URE model, CUREs engage large numbers of undergraduates in real research in a core classroom environment along with peers (Auchincloss et al., 2014; Elgin et al., 2016). For many students, participation in one or more CUREs may be the only research exposure they encounter during their undergraduate educations. A CURE is therefore intentionally designed to provide students with an "accurate," "true," "real," or "authentic" experience of research in stark contrast to the traditional cookbook science laboratory experiences (Auchincloss et al., 2014; Brownell and Kloser, 2015; Rowland et al., 2014). In Australia, the equivalent model of a CURE and the focus for this article is the authentic large-scale URE, or ALURE. The CURE and ALURE models have been framed separately, but they share a designed goal—engagement of undergraduate cohorts in research. In this article, we address the degree to which this represents an "authentic" scientific research activity by comparing our definition of authenticity (in the designed curriculum) with the literature definitions of authenticity
Graham F. Hatfull, Monitoring Editor Submitted February 15, 2016; Revised September 11, 2016; Accepted September 16, 2016 CBE Life Sci Educ December 1, 2016 15:ar79 DOI:10.1187/cbe.16-02-0102

*Address correspondence to: Susan Rowland (s.rowland1@auq.edu.au).

(C) 2016 S. Rowland et al. CBE-Life Sciences Education @ 2016 The American Society for Cell Biology. This article is distributed by The American Society for Cell Biology under license from the author(s). It is available to the public under an Attribution-Noncommercial-Share Alike 3.0 Unported Creative Commons License (http://creativecommons.org/licenses/ by-nc-sa/3.0)

"ASCB®" and "The American Society for Cell Biology $\circledR^{\prime}$ are registered trademarks of The American Society for Cell Biology. 
and the participating students' perceptions of authenticity (the experienced curriculum).

\section{ALUREs}

ALURE was initially developed as a means for engaging a group of self-selecting biochemistry students in a real research project (Rowland et al., 2012). Today, the model has been successfully adapted into a range of science disciplines, undergraduate levels, and institutions (Rowland et al., 2016). The ALURE model is described in detail in Rowland et al. (2012) and Rowland et al. (2016), and we briefly restate it here. ALURE allows students to complete research projects during the contact time that is normally dedicated to traditional laboratories or workshops during a unit of study. The research is novel, and the results are unknown. The results are of interest to (and communicated to) an external group of stakeholders such as a research group, other students, or members of the community. Each project is self-contained and takes no longer than a semester. Thus, in the Australian system, a student can complete an ALURE in 10-12 weeks with a commitment of around 3 hours of laboratory or workshop per week. The students must communicate their research results to the selected stakeholder audience as part of the project requirements.

In the learning design of ALUREs, our definition of authenticity was drawn from two sources, Jonassen (1999) and Weaver et al. (2008). Jonassen (1999) defined authentic learning as being situated in a real-world task that is personally interesting and assessed in a way that allows students to mimic real-world behaviors. Using this lens, ALURE is authentic because students 1) answer a research question with no known answer (using techniques and approaches appropriate to their field of study) and 2) are assessed on their ability to communicate their (novel) findings to an "audience who cares" (Rowland et al., 2014).

Because the research problems are unsolved and the outcomes are relevant to their audiences, students may make novel discoveries that could benefit invested groups. The conception of authentic laboratory learning held by Weaver et al. (2008) includes the element of "discovery," and this is the second source we drew on when designing the ALURE model. The importance of discovery as a defining component of research has recently been reinforced by work from Corwin et al. (2015a,b). All ALUREs incorporate the generation of new data and their subsequent communication, while engagement in other research practices, such as experimental design, changes for individual implementations (Rowland et al., 2016).

This level of flexibility resonates with the dual definition of authentic science proposed by Spell et al. (2014). They suggest that authentic science teaching and learning programs can encompass "process" or "product" (see Table 1). In process programs, the focus is on developing student skills and understanding of science, while product programs focus on generating data. They suggest the two models need not be mutually exclusive but can be flexibly integrated in CUREs. These two contrasting ideas are integrated into each ALURE, while the level of student responsibility or autonomy varies. We therefore define "authentic" research experiences as those that flexibly engage students in research practices while they work on novel experimental questions to produce potentially publishable data for audiences who are interested in the scientific outcomes of their work.

\section{Context for This Study}

The educational context for this study is a case study of a single instance of an ALURE. At a large, research-focused Australian university, second-year science students can enroll in Biochemistry and Molecular Biology (BIOC2000). This large course (more than 700 students per annum) serves a diverse student population in terms of preparation, program of enrollment, and career goals. As part of BIOC2000, students complete a 10-week (30-hour) laboratory program, and they have the option to self-select into one of two experimental streams: ALURE or Laboratory Experience for Acquiring Practical Skills (LEAPS). The latter represents a more traditional laboratory experience. Around 60 students from the BIOC2000 cohort participate in the ALURE stream. They work together in groups of three or four to conduct replicates of a semester-long research project in which they purify and test the efficacy of a recombinant spider toxin as a pesticide and communicate their findings back to a research group at the university. In the LEAPS, the students focus on building skills in molecular biology and protein chemistry as they complete a sequence of practical exercises that are temporally arranged (for a full explanation of the series, see Rowland et al., 2012). For both LEAPS and ALURE students, the ability to progress through their laboratory exercises depends on the outcomes of previous laboratory sessions. According to our definition, LEAPS is not an "authentic" research experience, because students are not generating new data and the results they produce are not of any intrinsic value to a group of stakeholders.

Is ALURE truly authentic as a research experience? Does it provide a more authentic research experience than LEAPS? This question cannot be answered without both challenging our definition of "authentic" and examining the student perception of the "authentic" research activity we have designed.

Consequently, in this research paper, we examine four questions:

1. According to the wider literature on authenticity in science education, is ALURE designed to be an authentic research experience (and, conversely, is LEAPS "inauthentic" as a research experience)?

2. How do students in ALURE and LEAPS experience scientific research "authenticity" in their programs?

3. How does the student experience of scientific research "authenticity" in ALURE and LEAPS mirror the ideas surrounding authentic science education in the literature?

4. Have we succeeded in delivering an "authentic" large-scale URE to the ALURE students?

\section{THEORETICAL FRAMEWORK: LITERATURE DEFINITIONS OF AUTHENTICITY Why Define "Authenticity"?}

Apart from the reasons stated above, we feel that there are two other arguments supporting an exploration of how the term "authentic" is used in science education. First, CUREs are becoming increasingly embedded into tertiary (college-level) STEM teaching practice and look set to become a fixed part of undergraduate science education. In Australia, many ALUREs are delivered each year at multiple different universities, and the number is growing (Rowland et al., 2016). In light of a recent focus on how CUREs are evaluated (versus the claims 
TABLE 1. Literature definitions of "authentic"

\section{Category 1: Science education at the K-12 level}

We designed learning environments that, in our view, shared some crucial features with everyday environments of scientists, engineers... . Because of these shared features, we used the adjective authentic to distinguish our learning environments from more traditional ones. (Roth, 1997, pp. 378-379, citing Brown et al., 1989)

Here, we define authenticity as the quality of having correspondence to the world of scientists, and suggest that this can be achieved through "simulation" or "participation" models for establishing authentic learning environments. (Barab and Hay, 2001, p. 74, citing Barab et al., 2000)

Authentic scientific inquiry refers to the research that scientists actually carry out. (Chinn and Malhotra, 2002, p. 177)

Accordingly, authenticity is not taken to be located anywhere but is understood as emergent through the interactions of components of a system. Nevertheless, we have shown that the presence of certain components is more conducive to the emergence of authenticity. For instance, involvement over sustained periods of time as well as possibilities for project ownership were seen as important yet not defining variables. (Rahm et al., 2003, p. 752)

Practical science in out-of-school contexts is more "authentic" than much of what goes on in school laboratories when it helps demonstrate or it replicates the sort of work that scientists frequently undertake in modern science, or if it is perceived as having relevance to solving real-life problems. (Braund and Reiss, 2006, p. 1378)

Authentic science inquiry requires that students actively produce authentic scientific knowledge-knowledge driven by their own questions with/in the world-and distribute their knowledge through written and oral forms of communication, rather than simply consuming and regurgitating pre-packaged knowledge sets. Although authentic science inquiry will include known concepts and theories of science, it may remain unique to the particular learning situation. (Rivera Maulucci et al., 2014, p. 1145)

Authentic science inquiry refers to activities that model the processes used by practicing scientists. (Peffer et al., 2015, p. 2)

Authenticity is the degree to which students, not teachers or curriculum designers, map their learning activities to the external world. (Radinsky et al., 2001, p. 407)

Category 2: Addressing science education at the tertiary (college) level

Investigations are "genuine" because the question is of interest to the research or management community, the outcome of the project is unknown to the students and to the teacher, and so the class is doing real research. (D'Avanzo, 1996, p. 92)

Authentic scientific inquiry is that which scientists conduct in everyday practice. (Schwartz et al., 2004, p. 612, citing Roth, 1995)

Half of the liberal arts colleges (50\%) report using open investigations in their introductory courses. For students this represents an exposure to authentic research early in their careers. (Sundberg et al., 2005, p. 528)

Authentic inquiry: The problem, procedures/design, analysis, communication, and conclusions are for the student to design. (Buck et al., 2008, p. 54)

An important question remains about whether a course-based research experience can result in the same or equivalent educational benefits to students and can be authentic research-that is, scientific activity that can, at some level, contribute to publishable work. (Weaver et al., 2008, p. 579)

We use the phrase authentic research to reference opportunities for learners to work on scientific research with practicing scientists. ... In short, authentic scientific research introduces undergraduates to the real world of science (or at least a version of real science) in the form of apprenticeships. (Sadler and McKinney, 2010, p. 43)

A course that is intentionally designed to incorporate hallmarks of authentic biological research, such as the following:

- development of student-generated research questions whose answers are currently unknown,

- longitudinal focus on one set of research questions over the length of the course,

- implementation of experimental designs that are not predetermined,

- collaboration among peers, and

- presentation by students of results and ideas for future research. (Brownell et al., 2012, p. 37)

Education reform toward authentic science instruction includes definitions of authentic science as a process (involving critical thinking, hypothesis generation experimental design, data analysis, and scientific communication) or as a product (novel results, new discoveries, and publishable data). (Spell et al., 2014, p. 103)

Authentic research lab activities are similar to the more well-known inquiry experiments but differ in that students' experimental results contribute to real research projects conducted by scientists. (Winkelmann et al., 2014, p. 247, citing Weaver et al., 2008)

These experiences are seen to benefit students because, unlike their more traditional laboratory course experiences, these authentic experiences allow for students to see how science is conducted in a day-to-day manner. (Gardner et al., 2015, pp. 61-62)

Category 3: Addressing the theory and practice surrounding authenticity in education

Authentic activities then, are most simply defined as the ordinary practices of the culture. (Brown et al., 1989, p. 34)

A science education that is tending toward authenticity would be one that draws in as many relevant aspects of science as are appropriate at a given point in the student's life. (Martin et al., 1990, p. 552)

To meet the test of "authenticity," situations must at least have some of the important attributes of real-life problem solving, including ill-structured complex goals, an opportunity for the detection of relevant versus irrelevant information, active/generative engagement in finding and defining problems as well as in solving them, involvement of the student's beliefs and values, and an opportunity to engage in collaborative interpersonal activities. (Young, 1993, p. 45) 
Authentic can also simply mean personally relevant or interesting to the learner.... Authentic problems ... engage learners; they represent a meaningful challenge to them. (Jonassen, 1999, p. 222)

One way out of the conundrum facing science education is to make it much more "authentic": as closely alike the conduct of science per se as is possible under the current conditions of mass education. A more authentic science education would have a number of characteristics. (Gilbert, 2004) (p. 116)

(i) Authentic Science Learning Contexts are learning experiences closest to being the most authentic (realistic) that thus provide students an opportunity to engage in the real-work of scientists in real-world or highly realistic situations. (Murie, 2014, p. 10, citing Braund and Reiss, 2006)

(ii) Authentic science learning implies that students are exposed to a more accurate picture of how science is done by experiencing science as scientists do. (Murie, 2014, p. 10)

Finally, the teacher may use open inquiry, also referred to as authentic inquiry, in which the students are responsible for identifying the problem and designing ways to investigate it. Open inquiry is the least structured and most learner-centered level of inquiry. This open inquiry is the kind of research conducted by scientists. (Wood and McComas, 2014, pp. 52-53, citing Bell et al., 2005; Colburn, 2000)

Authentic learning experiences are those in which learners are assisted in some way to construct and refine concepts in personally meaningful ways. (Squires, 1999, p. 2)

Note: Bold for emphasis is ours, except in Wood and McComas (2014).

made about their efficacy), now is an opportune moment to clarify the notion of authenticity (Linn et al., 2015). Second, when undergraduate students complete a learning experience that is billed as "authentic," their views of "real" science and research will be impacted (Cartrette and Melroe-Lehrman, 2012; Gardner et al., 2015; Linn et al., 2015). It is important that when we use the word "authentic" we do not give students a false expectation about the practices of scientists and scientific researchers. It is also important that science educators have a working definition of authenticity that they can use, confident in the knowledge that it takes all of the literature into account.

\section{Establishing a Theoretical Framework for Authenticity}

To establish a theoretical framework for this study, we conducted a literature review around the concept of authenticity in science education. Google Scholar and ERIC were used as the primary databases; the search was not limited to specific journals or a set time frame. Search terms were chosen to target the use of the words "authentic" and "authenticity," with reference to science education and STEM-based undergraduate research, and included "define authentic research," "what is authentic science," "authentic undergraduate science research," and "authentic science inquiry (or research) undergraduate" (note in each case "authentic" is used as a qualifier rather than as an attribute in itself). Papers were chosen if authors provided their own definition of the term, that is, they did not just quote another paper.

The chosen papers use the lenses of education and learning to address the concepts of authentic science, authentic research experiences, authentic scientific enquiry, and authentic science processes. We did not attempt to separate or tease out these themes, as often they were intimately entwined in the papers we found. The extracts included in Table 1 are those that we felt were most appropriate for capturing the authors' definition of authentic(ity) in each paper. References to "authentic assessment" were excluded, because these focus on the measurement of student learning outcomes rather than their learning experiences or processes.

Twenty-six definitions were identified as relevant to this study across the past three decades (Table 1). We have placed the definitions into three categories. Papers in the first two cat- egories address science education at the K-12 level (category 1) and the tertiary (college) level (category 2). Sources in category 3 provide in-depth discussion of theory and practice surrounding authenticity in education (Brown et al., 1989; Young, 1993; Jonassen, 1999), including science education (Martin et al., 1990; Squires, 1999; Radinsky et al., 2001; Gilbert, 2004; Murie, 2014; Wood and McComas, 2014). Category 3 resources help situate the science education authenticity discussion in the broader authenticity-focused education literature. Readers should note that the table only contains extracts from the sources in which "authenticity" is explicitly defined to capture a sense of how this term in particular is used. The exception is D'Avanzo (1996), whose definition includes the synonym "genuine."

Authors in category 1 describe their conceptions of authenticity as it applies to K-12 science education. Peffer et al. (2015) and Chinn and Malhotra (2002) describe "authentic science inquiry" as being what scientists "do." This theme, which encompasses the idea of experiencing science in the way scientists themselves pursue it, is the most common theme overall in the literature (see Table 2). Chinn and Malhotra (2002) argue that authentic scientific activity involves cognitive work around problem solving that is qualitatively different from the simple inquiry tasks frequently used in school curricula. Peffer et al. (2015) acknowledge this argument and consider it essential to incorporate design and problem-solving practices when designing for authenticity. Braund and Reiss (2006) also define authentic science as the work that scientists do, extending the definition to include the element of being relevant in real-life contexts.

Barab and Hay (2001) describe two possible models that foster authentic science learning: participation and simulation. The "participation" model refers to programs similar to a URE that take place outside the classroom. The "simulation" model, in contrast, is classroom based. It involves students "frequently doing the practices of science" (pp. 74-75). Barab and Hay state that, by replicating the science that scientists do, students experiencing a simulation environment have a greater opportunity than participation students to "take ownership" of their work. Like other category 1 authors, these authors also agree that engaging students in "what scientists do" is authentic. 
TABLE 2. Synthesis of the literature definitions of "authentic" learning in science

\begin{tabular}{lc}
\hline Aspect or definition of authenticity & Times occurring \\
\hline $\begin{array}{l}\text { Experience of what scientists "do" } \\
\quad \text { (practices), how science is done, and }\end{array}$ & 15 \\
$\quad$ what science "is" & 7 \\
Ownership/personal relevance to student & 6 \\
$\begin{array}{l}\text { Experimental design; question/hypothesis, } \\
\quad \text { including by students }\end{array}$ & \\
Results are novel/publishable/contribute & 4 \\
$\quad$ to existing research & \\
Communication & 4 \\
Critical thinking & 3 \\
Data analysis & 2 \\
Peer teamwork & 2 \\
Audience (real problem) & 2 \\
One project for the course duration & 1 \\
"Emerges" from constituent parts of & 1 \\
$\quad$ experience & \\
Extended participation (in research) & \\
"Open investigations" & 1 \\
"Ill-structured and complex goals" & 1 \\
Appropriate for the learner education level & 1 \\
\hline
\end{tabular}

In a stark contrast to the work just described, Rahm et al. (2003) perceive authenticity as being an "emergent" quality of the participants' experience and the context for the activity; thus, authenticity is founded in perception. They critique the simulation and participation models and argue that placing the student and professional practice together is not sufficient to create authenticity. They suggest that educators should reject the idea of "pre-authenticating" an educational experience and should, instead, consider that the learner will perceive authenticity through the complexity of collaboration, ownership, and meaning-making.

Later authors in this category appear to take a pragmatic approach to implementing the ideas of Rahm and coworkers. Roth (1995) describes authentic science environments in the classroom that incorporate many of the practices of scientists and mimic the character of the work scientists perform. In Roth's classroom the teacher adopts a collaborative role, the students direct their own learning, and the activities are authentic because they cognitively engage students in the same way scientists think and include the need for students to defend their work. Rivera Maulucci et al. (2014) draw on epistemological theory that advocates for students to learn in social contexts while they address a personally relevant problem. Consequently, they state that what students learn about how science is done, and about themselves in doing science, is the most important feature of an authentic science learning activity. Radinsky et al. (2001) describe an educational model that attempts to give students an authentic experience by collaborating with a technology company in a "mutual benefit partnership." Importantly, Radinsky and colleagues state that authenticity lies in the ability of students to make meaning from their experience; the authors say: "We want them to see that they can DO something meaningful and contribute to the 'dialogue"' (p. 411).

Educators who are writing about college-level education (category 2) have frequently moved beyond the K-12 idea that their students should primarily experience "what scientists do." It is no longer enough for these authors that their students experience science without engaging actively; instead, the students need to be adopting an expert stance, actually doing science as a scientist and learning high-level science skills. This makes sense, as students in college science programs are positioned to become scientists in the workplace. Category 2 authors also frequently talked about authentic research practice; they were the only ones to include "novel results" $(n=4)$ in their definitions, and they had a near monopoly on the term "experimental design" ( $n=5$ of 6 total in Table 2).

Weaver et al. (2008) state that the authentic research experience hinges on the creation of potentially publishable data. This view falls into the "product" category of authentic research (Spell et al., 2014). Weaver et al.'s (2008) conception of authenticity was included by Winkelmann et al. (2014) in the rationale for the design of a first-year chemistry "research-inspired" inquiry laboratory series, which lends weight to the idea that production of high-quality data ties to authenticity in research education.

Sadler and McKinney (2010) also include the generation of novel results as a feature of authentic science research activities. They cite the "typical" example of authentic activity as something that takes place outside a classroom and in collaboration with members of a research group-in other words, an apprenticeship URE. They describe the goals for such programs as exposure to the true nature of science work and generating new findings. These authors also, however, state that authenticity is about students experiencing "what science is like," and we find similar definitions from Gardner et al. (2015) and Schwartz et al. (2004). The latter authors also feel that authenticity comes from engaging students in what scientists do and how science is done. This brings us to our second main theme for the category, which Spell et al. (2014) refer to as "process."

Along with the idea that an authentic research activity must allow students to generate new data, Weaver et al. (2008) also discuss the processes that embody real science practice. These include "observation," "questioning," "experimental design," "data collection," "data analysis," "repeating," and "reporting/ peer review." Each of these is immediately recognizable as a feature of our own CUREs/ALUREs (Rowland et al., 2016). Brownell et al. (2012) also list authentic science practices and use these to define their program. Again, many of these are not unfamiliar in the context of UREs and CUREs. Buck et al. (2008) argue that authenticity only eventuates when students design all of these elements themselves, which (rather disturbingly) renders a URE inauthentic if the students are given any scaffolding at all.

We agree with Weaver et al. (2008) and Auchincloss et al. (2014) that "discovery" sets authentic research-based laboratory learning apart from inquiry teaching. Most science practices can conceivably be taught in a variety of settings, but authenticity comes from that which can only exist in a real research setting-novel results that contribute to the field of research. The idea of a "blended" or flexible model that includes both "process" and "product," or practice and discovery, provides a design solution for programs that aim to provide authenticity alongside scaffolded learning of the scientific process.

We should also note the definition from Sundberg et al. (2005) here. Those authors state (without elaboration) that "open investigations" provide undergraduates with authentic experiences of science research. In our literature review, we 
came across several other authors who use the term "authentic" without explaining or defining it. We have not included these in our analysis, but the multiple instances back up the suggestion from Auchincloss et al. (2014) that the word "authentic" has a level of implied meaning that can create confusion and controversy.

Four authors in category 3 are writing from a more theoretical perspective about authenticity in science education. Murie (2014) and Wood and McComas (2014) describe elements of authentic learning contexts and authentic enquiry, respectively; each advocates for the students doing work that mirrors the work of scientists. Gilbert (2004) suggests some interesting characteristics of authentic science education that include depicting the processes of science, incorporating creativity, and involving technology in solving "human problems." We do not list these in Table 1 because the wording is unique; however, we acknowledge that they are valuable additions to the canon.

Perhaps the most thought-provoking reference in this category comes from Martin et al. (1990), who point out the ambiguity in the term "authenticity" and state that "unless thoughtful attention is given to the richness implicit in an authentic portrayal of science, the phrase 'authentic science' runs the danger of becoming just another buzzword of science education" (p. 552). They illustrate the complexity of the term by listing nine different conceptions of authentic science. These include technical, epistemological, philosophical, private, public, personal, and historical authenticity. What they demonstrate, and ask others to consider, is that science (or authentic science education) is not limited to one context, way of thinking, or purpose. Finally, as per the definition in Table 1, these authors advocate for approaching authenticity as it relates to the learner. As we have seen, this is a recurrent theme in the literature and one to which we will return.

The four remaining theoretical sources in category 3 provide a rich, historical perspective in our investigation of authenticity in science education. As we have already mentioned, the work of Jonassen (1999) has been important in defining the ALURE model. Again, the learner is central to defining or creating authenticity in the context of this constructivist epistemological domain. The author also feels that activities in which students are doing "real-world tasks" without engaging in "cognitive challenges" capture only some of what authentic learning means.

Squires (1999) deals specifically with the development of educational software in an approach that we would now call "learning design." The author takes a constructivist view and describes "cognitive" authenticity, involving problem solving, ownership, and input from the student. He also describes "contextual" authenticity, in which the environment mimics a real world, there is collaboration, and the teacher acts as a guide.

Our final two educational theory papers (Brown et al., 1989; Young, 1993) address situated cognition, a concept that often arises in the literature surrounding UREs (e.g., see Corwin et al., 2015a,b). Young (1993) wrote his paper in response to Brown et al. (1989) and summarizes the earlier paper by stating that authenticity "enables students to immerse themselves in the culture of an academic domain" (p. 43).

In Table 2, we synthesize and summarize the 26 definitions we have just discussed into a list of 15 common themes and aspects of authentic science learning. Each time a definition included a theme, it was counted as one instance of that theme or aspect; one definition may contribute multiple times to one or more theme.

From our analysis, it is clear that there is no consensus view on what the word "authenticity" means or how it should be enacted in a science curriculum. There is evidence, however, that the most frequent conceptions of authenticity in science education involve the ideas that students experience what scientists "do," how science is done, and what science "is." This is a loose definition, but it appears to encompass most of the concepts that authors use as the foundations for their design and delivery of "authentic" science education. There is debate in the literature about the relative value of "process" and "product" as part of science research experiences. There is also debate about the ability of an educator to preauthenticate an URE and the wisdom of relying on students to perceive authenticity when they are simply placed in or exposed to the process of science. Several authors assert that authenticity comes from students engaging with the process of science, collaborating with others, and making meaning from the activity for themselves.

We see many aspects of ALURE design that closely mimic the educational design elements in Table 2. ALURE students experience much of what research scientists do, including making their own experimental materials, performing a series of experiments that are temporally dependent, collaborating with peers, failing in their experimental attempts, finding (or failing to find) novel results, and communicating those results to audiences that see the data as valuable. Consequently, we can address our first research question around ALURE authenticity by stating that ALURE is designed to provide students with an authentic research science learning experience and that students engage with both the "process" and "product" aspects of an authentic research experience.

When we examine LEAPS, we rather surprisingly see that there are also authentic elements in this procedure-based experimental series. The LEAPS students do not generate new data, generally their experiments do not fail, and there is no "interested audience" for their tried and tested results. They do, however, perform experimental methods that are used in modern science laboratories and their experiments are temporally dependent. The difference between LEAPS and ALURE is that the ALURE students are researching something new (and producing a "product"), while the LEAPS students are not (essentially they only engage in a simplified "process"). LEAPS has not been designed as an "authentic" research experience but it could well be described as an authentic laboratory process experience.

How do the students experience the enacted ALURE and LEAPS curricula? Do they see them as authentic science research experiences? Using the findings from this section as a framework for our investigation, we examine and compare the student experience of ALURE and LEAPS.

\section{METHODS}

\section{Participants and Context}

The participants in this study were students enrolled in BIOC2000: Biochemistry and Molecular Biology, a second-year (junior-level) course at a large, research-intensive, public university in Australia. The cohort of BIOC2000 in $2014(N=$ 633) participated. Each year, 60 BIOC2000 students enroll in ALURE, while the remainder of the cohort (between 550 and 700 students) complete LEAPS. 
Entry to the ALURE program is not random or unbiased. Students are selected into this ALURE on the basis of a short, submitted expression of interest (EOI) in which they state their career goals, their majors, and their reasons for wishing to enter the ALURE. Around 100 students each year $(\sim 15 \%$ of the cohort) submit an EOI. Sixty students are chosen, as this is the capacity of the tutor group that can be accommodated for the ALURE. Students are more likely to gain entry to the program if they are enrolled in a science-related program (as opposed to a health-related or engineering-related program). They are also more likely to gain entry if they state they are 1) interested in or considering a career in research or 2) unsure of or exploring their career options. Students who state they wish to be medical doctors are unlikely to gain entry to the ALURE. Students are not screened for grade point average or previous failures of BIOC2000. We can state that students who enter ALURE are more likely to be interested in engaging with research than students who enter LEAPS.

\section{Design and Delivery of the ALURE}

The design and delivery of the ALURE and LEAPS programs has been described previously (Rowland et al., 2012). The project offered in the 2014 iteration of ALURE changed to incorporate an examination of a different set of proteins, and this project design will be published elsewhere. The new ALURE program mirrors the timing of the LEAPS program, and the ALURE students generate novel results that are relayed to a research group on campus. ALURE students communicate their research in the form of a research paper in the style of a six-page Molecular Cell paper. These authentic design features are the same as those reported in Rowland et al. (2012). The LEAPS program is the same as that described in Rowland et al. (2012).

\section{Method for Data Collection}

Data around the student perceptions of authenticity were collected using reflections that BIOC2000 LEAPS and ALURE students completed as part of a postsurvey and a final course assignment (Supplemental Table S1). The reflections were elicited using a "roses, thorns, buds" prompt (Luma Institute, 2014); we ask the students to identify one positive (rose) and one negative (thorn) part of their laboratory experiences, then reflect on one new understanding, change in perspective, or possibility for their futures (bud). This use is slightly different to the form described in Luma Institute (2014), and we have not found it in another published reference. The ALURE program was named "ALLURE" (Active Learning Laboratory Undergraduate Research Experience) at the time of data collection, while the LEAPS program was called "LEAPS." The students in ALLURE and LEAPS were not prompted directly to comment on authenticity. In the final course assignment, marks were given to students for supplying a reflection that adhered to the requested roses, thorns, buds structure; marks were not given for particular words or sentiments in the reflections. These criteria were provided to the students. The postsurvey was not graded. We can state with confidence that the students' reflections on "authenticity" are free and unprimed.

\section{Method for Data Analysis}

Institutional ethical approval was gained for this study, and only students who gave informed consent to have their reflec- tions analyzed were included. Because reflections were collected using two methods, the files were checked, and duplicate texts were discarded. The combined data set of screened reflections included 94 unique ALURE and 510 unique LEAPS reflections (some students submitted two different reflections). Components from the reflections that referred to the laboratory experiences (rather than to other parts of the enacted curriculum) were extracted, and these were the only parts of the reflections that were coded. The sources were imported into Nvivo and coded deductively by two authors (Y.H. and J.L.-T.) using Nvivo and a framework from Hunter et al. (2007).

The framework (Supplemental Table S2) that was applied addresses activities that Hunter and colleagues defined as key learning gains from UREs. This framework is validated for use on undergraduate student researcher statements (Hunter et al., 2007; Thiry et al., 2011). It concisely categorizes the types of learning students experience (as opposed to categorization of skills and techniques that students describe). The parent nodes applied in deductive coding were based on those used by Hunter et al. (2007) and include "Thinking and working like a scientist," "Becoming a scientist," "Personal and professional gains," "Clarification, confirmation, and refinement of career and education paths," "Enhanced career and graduate school preparation," "Skills," "Generalized other gains," and "Working independently." The entire framework is shown in Table 3.

Interrater reliability between the two independent researchers' coding was established statistically in Nvivo, with an average kappa score across the framework of $\kappa=$ 0.702 ("fair agreement," according to the criteria of Fleiss [1981] as cited in Ishak and Bakar [2012]). Note that the student reflections were coded as a single cohort data set in deidentified alphabetical order rather than as two separate data sets for LEAPS and ALURE students. We cannot state that the analysis was blind to students' LEAPS or ALURE status, as respondents frequently mentioned their laboratory streams in their reflections.

\section{Exploration of Student Reflections Using Text-Search Queries}

To explore students' perceptions of authenticity in their experiences, we conducted text-search queries targeting the word "authentic" and synonyms or related terms. These terms, some of which were generated through the Nvivo text-search options, included "real," "actual," "genuine," and "everyday." All positively coded nodes in the framework for either stream were included in the query. These queries generated eight word trees. Quotes from students are taken directly from their responses and are not edited for reporting. An "A" or "L" following a quote indicates whether the student is in the ALURE/ ALLURE or the LEAPS cohort.

\section{RESULTS}

We explored the coded data using text searches and coding to address the following research questions:

1. How do students in the ALURE and LEAPS experience research "authenticity" in their programs?

2. How does the student experience of scientific research "authenticity" in ALURE and LEAPS mirror the ideas surrounding authentic science education in the literature? 
TABLE 3. Coding framework adapted from Hunter et al. (2007)

Parent category, subcategories, and nodes
Thinking and working like a scientist
Application of knowledge and skills
Understanding how to approach research problems and design
Understanding science research through hands-on experience
Understanding the nature of scientific knowledge
Increased knowledge and understanding of science and research work
Connections between and within sciences
Increased relevance of course work
Theory and concepts
Transfer between research and courses
Becoming a scientist
Demonstrated gains in behaviors and attitudes necessary to
becoming a researcher
Creative and independent approach in decision making
Intellectual engagement, initiative
Student takes "ownership" of project and shows responsibility
Greater understanding of the nature of research work and
professional practice
Identification with and bonding with science
Personal-professional

Establishing collegial working relationships with faculty advisors Establishing collegial working relationships with peers

Increased confidence in ability to do research, contribute to science, present or defend work, in "feeling like a scientist"

Clarification, confirmation, and refinement of career
and education paths

Clarification of which field to study

Greater knowledge of career and education options

Increased interest and enthusiasm for field

Introduced to new field of study

Validation of disciplinary interests and clarification of graduate school intentions

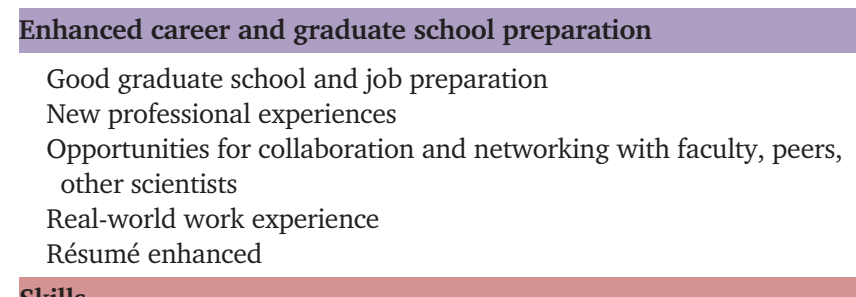

\section{Skills}

Communication skills

Computer

Information retrieval

Laboratory and field techniques

Presentation and oral argument

Reading comprehension

Work organization

Working collaboratively

Writing and editing

Generalized and other gains

Access to good laboratory equipment

Good summer job

Students learn a lot

\section{Working independently}

The parent and sub/child categories appear as in the original source, with the hierarchy determined by the two coders (J.L.-T and Y.H). Parent and subcategory nodes are colored. Uncolored child categories/nodes contain the subcoding for positive/negative/neutral statements. Within each child node, the coders organized statements from ALURE and LEAPS students as positive, negative, or neutral.

\section{Text Searches Reveal That Students Frequently Use the Word "Real" to Describe Their Scientific Experiences in the ALURE and the LEAPS Laboratory}

The text-search queries generated a number of word trees that allowed us to 1) visualize the target word and 2) gain an understanding of that target word's context by viewing the text that preceded and followed it. Four trees were generated (for each of the ALURE and the LEAPS streams) in which more than one reference used the term in a laboratory-related context. The two largest trees are shown in Figures 1 and 2. Table 4 lists the themes and concepts encompassed by the eight trees.

Use of the Term "Real." In ALURE reflections, there are 41 instances of "real" (Figure 1), compared with 48 in the LEAPS submissions (Figure 2). As shown in Figure 1, ALURE students consistently used "real" as an adjective in relation to the authenticity of their experiences (e.g., real research, real life). This contrasts with the more diverse ways in which LEAPS students used the word "real" (see below). The ALURE students use of "real" are distributed across seven categories that we defined inductively (Table 4). In the largest category, the students describe gaining a "sense" of real research (15 instances, 36\% of "real" references). Equal numbers of references were found in which students describe ALURE as being different from their normal practical class and an insight into being in a real laboratory (six instances, $15 \%$ of "real" references). Students also described "doing a real project," "contributing to research," and "being able to apply theory"):

\section{"Although the LEAPS stream would have also conducted experi- ments with similar procedures, ALLURE relates those procedures to a real-life research project." (A)}

In the LEAPS word tree for "real" (Figure 2), 68\% of references relate to authenticity, while the remainder used "real" in other contexts and with other meanings (e.g., "being able to talk things out with others was a real help"). The 48 coded statements that relate to authenticity are spread over seven categories that we defined inductively. Students most frequently said that the technical aspects of LEAPS applied to or mimicked a real laboratory (13 references). The "real-life" design of the LEAPS series, gaining a sense of working in a laboratory, and applying theory in a "real" context were also frequent themes. Only five submissions mentioned gaining a sense of what research was like:

\footnotetext{
"The experiments we conducted with the real world experimental procedures used in labs today." (L)
}

"This whole series of practicals were based around a single aim, this allowed for a more realistic feel to the practicals, which allowed me to see what real research would feel like." (L)

Use of the Terms "Actual" and "Actually." We targeted the words "actual" and "actually" in the data, because they can be used as synonyms for "real" and "really." Half of the ALURE student reflections in the "actual" and "actually" trees used the words to imply the experience was authentic:

"I never realised how much work went into all these methods. It has helped me understand how an actual lab would run." (A) 


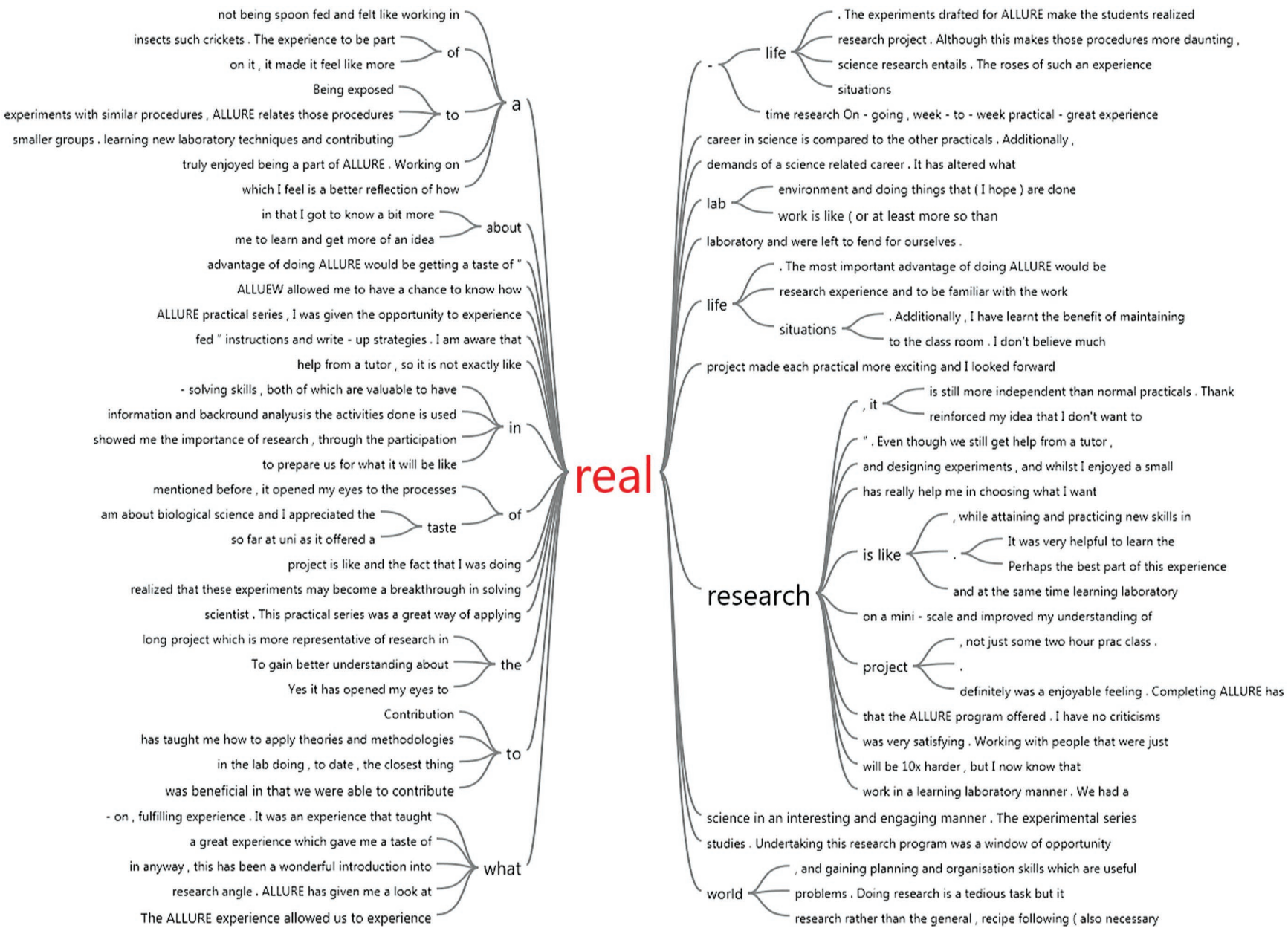

FIGURE 1. ALURE word tree: "real." The figure shows 41 references or instances of the word "real" in all positively coded ALURE reflections $(n=94)$. The context words on either side of the search word (in red) were lengthened to 10 words on either side of the word. The references are displayed in alphabetical order on each side, and therefore cannot be read from left to right to form a sentence or phrase. (Also see Supplemental Figure S1.)

"I really enjoyed getting to have some experience doing research. The work was interesting. I felt I was actually doing something." (A)

LEAPS students used "actual" and "actually" less frequently and in a different way. While ALURE students felt they were contributing to "actual" research that had unknown or meaningful results, LEAPS students described doing "actual" practical work, gaining a sense of how research or laboratory work is done, and applying theory in practice:

"Undertaking these practicals has made my future career plan feel more real. I feel more knowledgeable on what actually occurs in the laboratory." (L)

Use of the Terms "Authentic" and "Genuine." There were three references to "authentic" in the ALURE coding. No LEAPS students used "authentic," but two used the term "genuine." Both LEAPS and ALURE students used these words to refer to their experiences of being in a laboratory or of doing research.

We believe it is important to note the students' vocabulary here. When they are unfettered by particular word prompts, they consistently rely on the words "real" and "actual" (rather than "authentic") to describe their experiences. This gives us pause as investigators. It indicates we need to be careful with the use of antiquated or overly scholarly words when we approach students for comments and, instead, recognize that they will use different and potentially unexpected words to express concepts and impressions we are examining.

\section{Coding Analysis Reveals That Student Perceptions of Both LEAPS and ALURE Align with the Most Common Literature Definitions of Authenticity}

Although the word searches uncovered some student discussions of authenticity, the absolute numbers of reflections represented in the results ( $n \leq 124)$ were only around $20 \%$ of the total available pool of source reflections $(n=604)$. To more fully and more systematically examine the students' perceptions of their laboratory experiences, we queried the coded data, using the top two literature definitions of authenticity shown in Table 5.

We will focus the remainder of our analysis on these categories, which we call "theme 1: experiencing what scientists 'do' and how science is done" and "theme 2: ownership." 

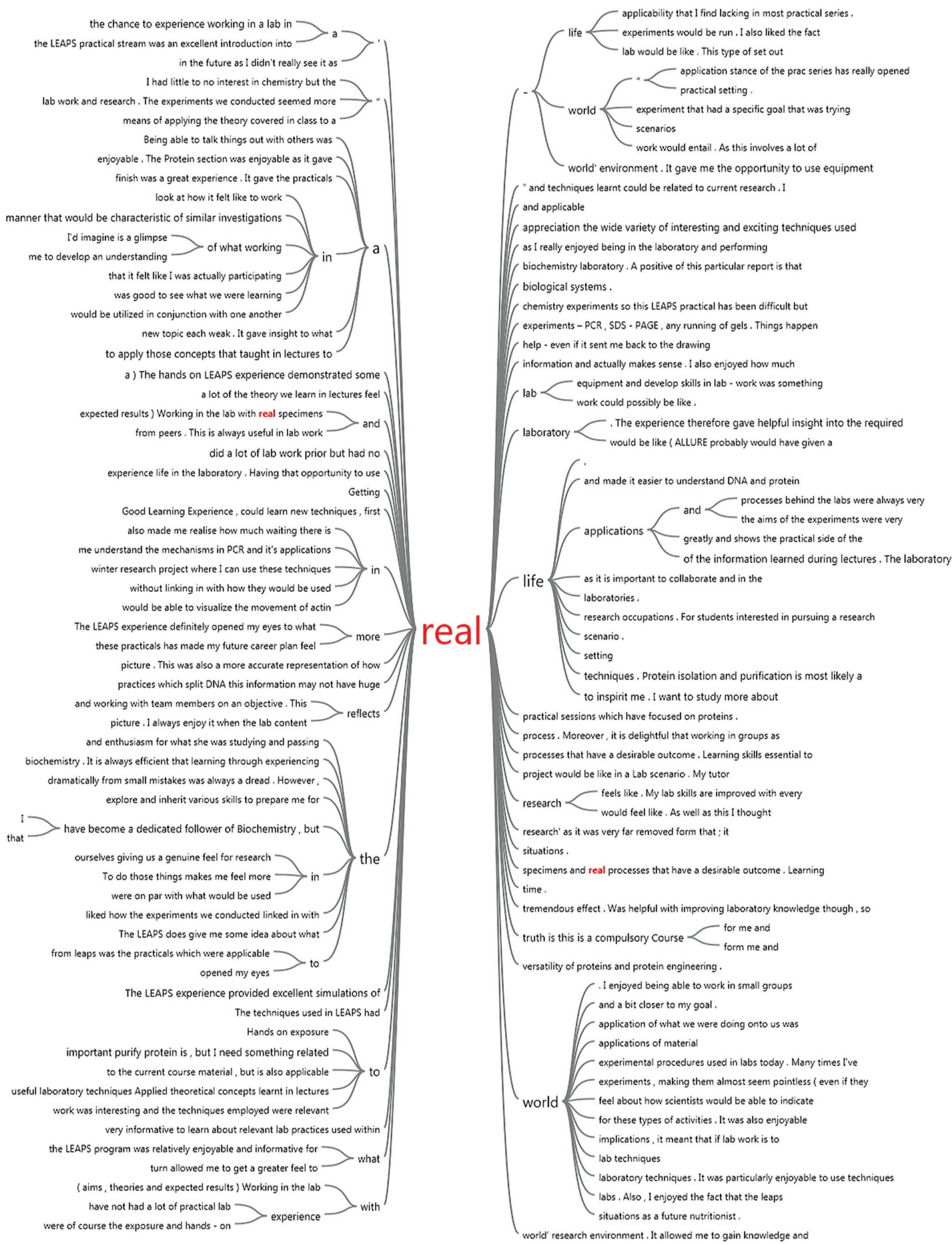

FIGURE 2. LEAPS word tree: "real." The figure shows 71 references or instances of the word "real" in all positively coded LEAPS reflections $(n=510)$. The context words on either side of the search word (in red) were lengthened to 10 words on either side of the search word. The references are displayed in alphabetical order on each side, and therefore cannot be read from left to right to form a sentence or phrase. (Also see Supplemental Figure S2.) 
TABLE 4. ALURE and LEAPS student perceptions of authenticity

\begin{tabular}{|c|c|c|}
\hline \multicolumn{3}{|c|}{ ALURE (94 sources, 53 uses of stem words) } \\
\hline Stem word (instances) & Concept of authenticity categories & Count $^{\mathrm{a}}$ \\
\hline \multirow[t]{7}{*}{ Real (41) } & Gaining some sense of what research is like & 15 \\
\hline & Not like other practical classes/LEAPS & 6 \\
\hline & Insight into being in a real/professional laboratory setting or career & 6 \\
\hline & Participation in a "real" project & 5 \\
\hline & Contributing to research & 4 \\
\hline & Applied theory to "real" context & 3 \\
\hline & ALURE design mimics "real-life" & 2 \\
\hline \multirow[t]{5}{*}{ Actual(ly) (9) } & "Contribution to science" and "meaningful results" & 3 \\
\hline & Understanding of what working as a researcher/in a laboratory is like & 2 \\
\hline & Doing research/working on "actual" project & 2 \\
\hline & Actual research means unknown results & 1 \\
\hline & "Doing something" & 1 \\
\hline \multirow[t]{2}{*}{ Authentic (3) } & Being in a laboratory; doing research & 2 \\
\hline & The environment (was) & 1 \\
\hline \multicolumn{3}{|c|}{ LEAPS (510 sources, 71 uses of stem words) } \\
\hline \multirow[t]{6}{*}{ Real (48) } & Techniques and experiments apply to/mimic those of real labs and research & 13 \\
\hline & The experimental series (longitudinal design) mimicked real-life/a laboratory & 9 \\
\hline & A sense of what working in a laboratory or environment is like & 8 \\
\hline & Real-world context for course theory/content & 7 \\
\hline & Experiencing and using real experiments or equipment & 6 \\
\hline & Gained a greater sense of what research is like & 5 \\
\hline \multirow[t]{4}{*}{ Actual(ly) (21) } & Doing "actual" practical work & 8 \\
\hline & Understanding of how research is done & 4 \\
\hline & Understanding what "laboratory work is like" & 4 \\
\hline & Applying theory in practice & 5 \\
\hline \multirow[t]{2}{*}{ Genuine (2) } & "Laboratory work" & 1 \\
\hline & "Idea of real-world research" & 1 \\
\hline
\end{tabular}

aThe number of total references is calculated by Nvivo; some individual students use the query word multiple times in their reflection, so the count does not always reflect the number of students who used the word. The trees for "actual" and "actually" have been combined in both streams, due to their small size and shared stem. The table summarizes the results from Figures 1 and 2 and the other word trees that are not shown.

In addition to encompassing the most common literature definitions, these categories also provide an interesting means of comparing the LEAPS and ALURE student perspectives of authenticity. We have not included the third or fourth most common definitions ("experimental design" and "results are novel") as 1) neither stream engaged in extensive experimental design, and only a total of 10 students addressed this activity in their reflections; and 2) the results were not novel for the LEAPS students, so this theme is of little interest when we compare the two streams.

Theme 1: Experiencing What Scientists "Do" and How Science Is Done. To examine student reflections around "experiencing what scientists 'do' and how science is done," we analyzed the items coded to the framework node "greater understanding of the nature of research work and professional practice" in the parent node "becoming a scientist" (Table 3).

ALURE. There were 64 comments from ALURE students that matched theme 1. Eight students stated that their experience gave them insight into "what real lab work is like" because they were "doing things that are done in an every day lab." We align this with an experience of what researchers do, because the laboratory is a common work environment for the profession.
Thirteen students positioned themselves in the researcher role when they described a sense of what working in a laboratory and a laboratory career are like. Several statements indicated the students understood what researchers do. Many students described gaining insight into rather than actually experiencing the job of a researcher:

"I've learnt a great deal about what it's like to work in a lab."

"The primary positive in the ALLURE experience for me was that I gained insight into what the job of a research scientist is really like and the tasks that research scientists are expected to perform in their daily lives."

The most detailed reflections for theme 1 were from five students who described the everyday practices scientists use. Interestingly, all these excerpts refer to failure in some way. They demonstrate the students' understanding of how scientists approach experimental work, including failure, by listing the practices used in response to these challenges:

"The most important lesson I learnt was how to change your approach when your experimental approach fails. Not only does this force you to take your failure in stride, you also have to 
TABLE 5. Frequency of definitions of authenticity and comparison with LEAPS and ALURE definitions and student perceptions

\begin{tabular}{|c|c|c|c|c|}
\hline \multirow[b]{3}{*}{ Definition of authenticity: Literature } & \multicolumn{4}{|c|}{ Concept as defined in model and by students } \\
\hline & \multicolumn{2}{|c|}{ ALURE } & \multicolumn{2}{|c|}{ LEAPS } \\
\hline & Model $^{\mathbf{a}}$ & Student $^{\mathrm{b}}$ & Model & Student \\
\hline Ownership/personal relevance to student & $\sim$ & 26 & $\sim$ & 13 \\
\hline Experimental design; question/hypothesis, including by students & $\checkmark$ & & $\checkmark$ & \\
\hline Results are novel/publishable/contribute to existing research & $\checkmark$ & & - & \\
\hline Data analysis & $\checkmark$ & & $\checkmark$ & \\
\hline Outcome is unknown to all & $\checkmark$ & & - & \\
\hline Peer teamwork & $\checkmark$ & & $\checkmark$ & \\
\hline Audience (real problem) & $\checkmark$ & & - & \\
\hline One project for the course duration & $\checkmark$ & & $\checkmark$ & \\
\hline
\end{tabular}

rethink your approach, with what you are ultimately trying to achieve or show in mind. This is a glimpse into the day-to-day problems and frustrations researchers from all disciplines face."

"ALLURE gave a taste of what it would be like to work as an actual researcher. I now realise a lot more goes into research than expected. There is a lot of reading and hypothesising before any lab work gets done. Experiments need to be well planned and even then they can go wrong but it's all a learning curve."

From these reflections, it is clear that students do perceive ALURE as an experience that gives them some indication of what scientists "do." These excerpts also show there was more detail in the data than what we initially uncovered around the target word queries.

Many reflections indicate the students are gaining an understanding of the "nature of research" and the experimental and thought processes of science (16 references). Mostly, students describe the type of research they were exposed to in ALURE as "real," though others use the word "research" without further description (22 references in total).

Students mentioned several key research processes: use of controls, the need for an experimental pathway to a final result, collaboration, and the need for individualized approaches to research problems. This suggests students have gained some insight into how science works, whereas they did not have this understanding previously:

"It allowed me to know how research was like, for example, there were pre-calculations and experimental plans to be done before each prac and also results for each prac was carried on to the prac week after. It was a really good opportunity for people who have not done any research before to do original research."
"Research is not just sitting at a microscope, looking at something and analysing what is already there. Instead, research consists of finding something scientifically interesting, and putting it into an environment where you can learn more about it."

These examples show that students can identify the things they have learned about science through ALURE. Similarly, other students revealed what they had hoped to gain from ALURE and how their expectations were met:

"The reason I decided to apply for ALLURE was I wanted a more rigorous experience in how scientific research was conducted. ALLURE was exactly the program I wanted to be able to safely explore this option."

LEAPS. "Experiencing what scientists 'do' and how science is done" was by far the most populated theme for LEAPS students, 121 of whom made aligned comments. Nine students described feeling respect for and appreciating the work that scientists or laboratory technicians do, describing science as hard work and acknowledging that research projects may be difficult and lengthy. One student, for example, wrote that LEAPS “definitely made me appreciate what researchers and lab technicians do on a daily basis."

Nine students felt they better understood what happens in a working science laboratory. Specific laboratory methods were mentioned in three reflections. Eleven students also reflected more generally on how the techniques they used were relevant to real-life laboratories, to research, and to researchers themselves. The use of these techniques provided the students with more appreciation or understanding of what scientists "do" in their laboratories. Perhaps tellingly, LEAPS students frequently described their understanding of the working scientist's experience in an abstracted or distanced way, rather than placing 
themselves in the role of scientist. The quote below is an example of this abstraction:

"The Protein section was enjoyable. It gave a real world feel about how scientists would be able to indicate a specific protein which they did not believe had been discovered."

Although LEAPS is not designed to offer a research project, 14 students perceived the LEAPS laboratory sessions as representative of the work of a real environment. Others indicated their experience challenged their conceptions of laboratory work and, much like ALURE students, LEAPS students felt they gained insight into a science career:

\begin{abstract}
"It's been an interesting experience that made me realise there is more to a lab than I originally thought. This did make me see how interesting it could be and what can be achieved by it."

"I personally really enjoyed the LEAPS experience. It gave me a greater understanding of research-based careers and opportunities in science in a hands-on approach."
\end{abstract}

For students, the continuous, goal-oriented nature of the LEAPS practicals contributed to this understanding. Appreciation of the nature of research and recognizing the temperament of a scientist were also themes that arose in this group of reflections (45 references in total). The following quote is lengthy, but it exemplifies these ideas:

"It allowed to see the steps involved in experimental planning; the series of practical were all interconnected, and not just a random series of experiments without any order. As it was ordered, it required constant thinking of how the particular session fitted with the big picture. Thus, the LEAPS series allowed me to experience a glimpse of what working in a lab would be like; the good point was that the tutor was always there to oversee if we did any error, but at the same time, we had to take care of our own thus giving us enough independence to carry out our own experiment and learn how to be member of a lab and being responsible for you own part of the work."

Like the ALURE students, LEAPS students stated their practical experiences had allowed them to gain more understanding of what research is like or that they acquired an increased understanding of what research is. The language choices are similar between LEAPS and ALURE students; LEAPS students also used the term "understanding" and its synonyms. One student stated that he/she had increased his/her understanding of research because of the heightened independence students were given. Others attributed their understanding to the continuous, goal-oriented design of the practicals (some students indicated this was the first time they had experienced such a laboratory series). Students also indicated that their perceptions of the nature of research had changed as a result of their experiences. Statements about gaining a deeper understanding or changed perception of research represent the largest group for this theme (21 students):

"I found that this experience gave me an insight into what research in biochemistry is actually like. A lot of other practical classes attempt to portray this but I don't feel like I am taking part in a legitimate experiment."
"Very good laboratory experience, I particularly enjoyed the single continuous experimental series rather than lots of individual pracs, as this made it easier to see the bigger picture. This was also a more accurate representation of how real-life experiments would be run."

Six LEAPS students listed the activities they participated in during the program and described what they had learned from them:

"Actually getting to induce, cultivate, produce and purify green fluorescent protein was really cool. It had a reality and actuality to it that a lot of university courses don't provide."

Finally, three students felt they gained understanding of the nature of research work, stating that it requires care, dedication, and the facing of challenges:

"LEAPS has highlighted to me the amount of work that goes into scientific research, and the precision that is needed at each and every stage. I will take this into consideration when considering the possibility of a career in science."

Theme 2: Ownership. An entire framework parent node was dedicated to looking for instances of ownership (including "pride") in the data (Table 3). ALURE and LEAPS students described instances of ownership that are consistent with the project-ownership construct described by Hanauer et al. (2012).

ALURE. We coded 26 comments by ALURE students that indicated they felt ownership of the project. The most prominent type of reflection coded to this ownership node featured student descriptions of positive affect after accomplishing the long-term project goal. Being able to see the outcome of their work was satisfying. One student stated: "[The] best part of this experience was having an ultimate goal to reach by the end of semester and actually accomplishing that goal and seeing the outcomes of all the hard work."

Others recognized and enjoyed the need to be engaged in their work, with one student citing "a great sense of purpose and responsibility both within the lab, and for the project I was working on." Some students used the terms "ownership" and "responsibility" to describe how they felt about their projects, but ownership is not a concept that can easily be detected through key words. Many examples of ownership are evident from the affect students display in their reflections, rather than through their use of specific words; again, this idea has previously been described by Hanauer et al. (2012).

In the literature, authors stress personal relevance of the research problem or project as being important for authenticity. So far, we have not detected this wording of the concept in the reflections, but it is difficult to separate the constructs of "personal relevance" and "engagement." Certainly, it appears that students do feel some sense of the project being relevant to their interests.

LEAPS. Achieving a result and being given more responsibility in the laboratory are two aspects of the LEAPS experience that the students describe and that we link to "ownership." Thirteen LEAPS students made comments coded to this node. The 
students commented positively on their responsibility in the laboratory-they felt the work they did was their own. The design of the LEAPS practical series, in which the students perform a set of sequential experiments, surfaces as a theme that contributes to an aspect of authenticity. Like the ALURE students, the LEAPS students enjoyed working toward a goal and noted the rewarding feeling when this was achieved:

"It was great to feel like I was in control of an experiment in the lab that had a result applicable to me. That is to say it was my experiment therefore they were my results and I felt an authority on the subject."

"I also enjoyed how much of the experiments were up to us; we were allowed to be involved in nearly every single step, which allowed me to really understand what was going on."

\section{DISCUSSION}

Authenticity is a complicated concept to define in the context of science education. Many educators apply the term "authentic" with the assumption that the meaning will be understood by peers. Some describe authentic science as simply being "what scientists do" (Chinn and Malhotra, 2002; Murie, 2014), while others contest this idea, pursue the nonreductionist and nondeterministic perspective, and propose that authenticity arises out of the student's experience (Rahm et al., 2003; Rivera Maulucci et al., 2014). Despite the controversy over the meaning of the word "authentic" as it is applied in science education, the aim of creating a meaningful and life-relevant learning environment for science students is a commonly expressed priority. The questions we asked centered around the ALURE laboratory experience and the lived curriculum experienced by the student participants.

We have established our definition of authenticity, which informed the design of ALURE. When we compare our design with the literature conception of authentic research learning in science we find much material to support our ideas. ALURE students work on projects that produce "novel results" that "contribute to existing research" for an audience. They have opportunity to gain an experience of "what scientists do" and develop a sense of "how science is done." The ALURE model has other fixed features that align with the literature-communication, unknown outcomes, and peer teamwork.

The two core components of ALURE-the investigation of an unanswered question and the communication of results to an interested audience-provide a simple template and a new perspective for educational design of large-scale authentic UREs. We have provided an "authentic" educational model for class-based undergraduate research that is easily adapted to multiple contexts and can be delivered to large numbers of students at one time. We cannot make a final judgment about the authentic research experience in the delivered curriculum, however, without considering the student voice.

To explore how students perceive authenticity in ALURE and LEAPS, we analyzed student reflections for themes related to authenticity. As stated before, we have not designed the LEAPS laboratory experience to be an authentic research experience; however, one could argue that, based on the literature definition of authenticity, LEAPS provides an authentic laboratory experience, because students do complete activities and learn skills that would be commonly completed and used by laboratory technicians.

Our analysis of the students' use of "real," "actual/ly," "authentic," and "genuine" revealed some important themes, and we completed a more extensive analysis of the student reflections through application of coding nodes derived from a validated framework. The data were coded in relation to "experiencing what scientists 'do' and how science is done" and "ownership." Based on this analysis, the students' perceptions of authenticity in ALURE can be summarized as follows. ALURE allows students to conduct real research and gain insight into the nature of research work. Students are exposed to some of the processes used in everyday research, and they experience what working in a laboratory is like. ALURE allows them to face some of the challenges a researcher might encounter and struggle to overcome them. Research authenticity is present in students conducting experiments, as researchers do, with the view to discovering and contributing new information to a field of science.

Unlike ALURE students, LEAPS students were given no indication that their experience was like real research, so it was interesting that an unexpectedly high number of students referred to "research" in their reflections. While LEAPS is not an authentic research experience by our definition, this inquiry model clearly reflects some elements of authentic research practice, because the students in LEAPS are conducting experiments, keeping laboratory notebooks, and choosing some aspects of experimental focus and design-these are all aspects of what scientists do. Some LEAPS students felt that the continuous, goal-oriented design of the series of experiments was an indication of how real research might occur and what working in a laboratory would be like. They clearly equated performing a series of experimental steps with the approach that scientists use for their own laboratory work, and they saw this as an authentic science process (note the parallel with the "process" definition of authenticity from Spell et al. [2014]). In ALURE, students also do these things, but they are also immersed in a real research environment, and they truly do hypothesis-driven research that may produce novel results of interest to an audience other than their assessors.

The common outcome for both LEAPS and ALURE students was the shared perception that their experiences had provided them with insight into how a laboratory runs, how research is done, and what scientists do in their everyday jobs. We acknowledge that, within each stream, LEAPS and ALURE students alike perceive their experiences as authentic depictions of science and research. We did not design LEAPS to be an authentic research experience, and we cannot ignore the results from the LEAPS students. Their perceptions of authentic science draw attention to a recurrent theme we observed in the literature, which also relates to the student voice in determining authenticity.

As stated in the Introduction, one of the primary reasons for considering how authenticity is defined is the potential influence it may have on students' subsequent perceptions of science. Martin et al. (1990) acknowledge that "authenticity" to the student is not the same as "authenticity" to the more experienced teacher and that, "since authenticity is inextricably bound up in the learner, it is a highly problematic educational construct" (p. 552). Still, students who are not involved in 
learning and teaching that allows them to experience the many ways in which science is practiced may not form accurate ideas of what science is, let alone build the cognitive and affective skills essential to being a researcher.

The question of graduate destinations becomes critical at this point. The LEAPS students may not be developing the skills they need to be researchers; however, we know from previous work (Rowland et al., 2012) that they are not typically aiming for research careers. Instead, they are targeting careers in which analytical laboratories may well become their "authentic" environments. From their perspective, a perception of LEAPS as authentic science practice is valid, and our design, which allows them to practice useful, practical laboratory skills, does provide aspects of an authentic laboratory experience.

\section{IMPLICATIONS FOR EDUCATORS}

Earlier, we highlighted the definition of "authenticity" from Rahm et al. (2003), who describe it as emergent, dependent on the participants, and "grounded in the relations and negotiations among the worlds of teachers, students, and scientists as they collaborate in ... valid contexts" (p. 751). They critique the idea of "scientists' science" (Roth, 1995) as the preauthenticated model for authentic and valid science education. They also remind us that our role as educators is to provide students "with access to experience-based science activities that provide them with new perspectives and insights into the complex world of science that is part of everything we do" (p. 753). This is an argument for flexible design of undergraduate research and laboratory experiences and the acceptance of more than one model as valid and authentic.

We suggest that the solution to creating and defining authentic science education is not to agree with one singular definition but to be flexible based on intent and context. Martin et al. (1990) and Brownell and Kloser (2015) both suggest that we create authentic research experiences and "pitch" them at a level appropriate for the learner. This idea also incorporates the flexibility in the definition proposed by Spell et al. (2014), wherein educators can alternatively blend and incorporate aspects of process or product-based research.

On the basis of our findings, we can confidently state that ALURE is authentic when compared with most of the definitions we found in the literature, and also that it is a more authentic research experience than LEAPS. Many students who participated in ALURE found it to be an authentic experience, and for all intents and purposes, ALURE is living up to its name. LEAPS, from the perspective of the student participants, also has authenticity as an example of a series of experiments that require care and attention to technical detail in a working laboratory-many of the participants see this as authentic research practice, and they are right. This finding has prompted us to think further about the user experience of authenticity in education; we realize we had preauthenticated ALURE and pre-deauthenticated LEAPS.

\section{CONCLUSION}

We have shown that, even after decades of discussion, the field does not have an agreed-upon definition of "authenticity." What we have also shown is the importance of the student voice, something which is often criticized. Spell and colleagues
(2014) observed that "there is no one 'best' definition of authentic research" (p. 108), and it is likely that we will never agree on a single definition of the term. As is clear from our experience, students find an authentic science experience in two very different laboratory programs. This suggests that preauthentication and vetting of teaching activities is not always time well spent. Perhaps we should not argue voraciously and vociferously for or against the authenticity of a particular educational practice or design. Instead, the important thing is that we listen to our students and give them access to experiences in which they learn skills and ideas that are of value-and of use- to their futures.

\section{ACKNOWLEDGMENTS}

This work was supported by National Leadership Grant LE122279 from the Australian Office for Learning and Teaching.

\section{REFERENCES}

Auchincloss LC, Laursen SL, Branchaw JL, Eagan K, Graham M, Hanauer DI, Lawrie G, McLinn CM, Pelaez N, Rowland S (2014). Assessment of course-based undergraduate research experiences: a meeting report. CBE Life Sci Educ 13, 29-40.

Barab SA, Hay KE (2001). Doing science at the elbows of experts: issues related to the science apprenticeship camp. J Res Sci Teach 38, 70102.

Barab SA, Squire K, Dueber B (2000). Supporting authenticity through participatory learning. Educ Technol Res Dev 48, 37-62.

Bell RL, Smetana L, Binns I (2005). Simplifying inquiry instruction. Sci Teach 72, 30-33

Braund M, Reiss M (2006). Towards a more authentic science curriculum the contribution of out-of-school learning. Int J Sci Educ 28, 13731388.

Brown JS, Collins A, Duguid P (1989). Situated cognition and the culture of learning. Educ Res 18, 32-42.

Brownell SE, Kloser MJ (2015). Toward a conceptual framework for measuring the effectiveness of course-based undergraduate research experiences in undergraduate biology. Stud High Educ 40, 525-554.

Brownell SE, Kloser MJ, Fukami T, Shavelson R (2012). Undergraduate biology lab courses: comparing the impact of traditionally based "cookbook" and authentic research-based courses on student lab experiences. J Coll Sci Teach 41, 36-45.

Buck LB, Bretz SL, Towns MH (2008). Characterizing the level of inquiry in the undergraduate laboratory. J Coll Sci Teach 38, 52-58.

Cartrette DP, Melroe-Lehrman BM (2012). Describing changes in undergraduate students' preconceptions of research activities. Res Sci Educ 42 , 1073-1100.

Chinn CA, Malhotra BA (2002). Epistemologically authentic inquiry in schools: a theoretical framework for evaluating inquiry tasks. Sci Educ $86,175-218$

Colburn A (2000). An inquiry primer. Sci Scope 23, 42-44.

Corwin LA, Graham MJ, Dolan EL (2015a). Modeling course-based undergraduate research experiences: an agenda for future research and evaluation. CBE Life Sci Educ 14, es1.

Corwin LA, Runyon C, Robinson A, Dolan EL (2015b). The Laboratory Course Assessment Survey: a tool to measure three dimensions of researchcourse design. CBE Life Sci Educ 14, ar37.

D'Avanzo C (1996). Three ways to teach ecology labs by inquiry: guided, open-ended, and teacher-collaborative. Bull Eco So Am 77, 92-93.

Elgin SCR, Bangera G, Decatur SM, Dolan EL, Guertin L, Newstetter WC, San Juan EF, Smith MA, Weaver GC, Wessler SR, et al. (2016). Insights from a convocation: integrating discovery-based research into the undergraduate curriculum. CBE Life Sci Educ 15, fe2.

Fleiss JL (1981). Statistical Methods for Rates and Proportions, 2nd ed., New York: Wiley. 
Gardner GE, Forrester JH, Jeffrey PS, Ferzli M, Shea D (2015). Authentic science research opportunities: how do undergraduate students begin integration into a science community of practice? J Coll Sci Teach 44, 61.

Gilbert JK (2004). Models and modelling: routes to more authentic science education. Int J Sci Math Educ 2, 115-130.

Hanauer DI, Frederick J, Fotinakes B, Strobel SA (2012). Linguistic analysis of project ownership for undergraduate research experiences. CBE Life Sci Educ 11, 378-385

Hunter A-B, Laursen SL, Seymour E (2007). Becoming a scientist: the role of undergraduate research in students' cognitive, personal, and professional development. Sci Educ 91, 36-74.

Jonassen D (1999). Designing constructivist learning environments. In: Instructional-Design Theories and Models, ed. CM Reigeluth, New York: Routledge.

Linn MC, Palmer E, Baranger A, Gerard E, Stone E (2015). Undergraduate research experiences: impacts and opportunities. Science 347, 1261757.

Luma Institute (2014, January-February). A taxonomy of innovation. Harvard Business Review. https://hbr.org/2014/01/a-taxonomy-of-innovation (accessed 10 September 2016).

Martin B, Kass H, Brouwer W (1990). Authentic science: a diversity of meanings. Sci Educ 74, 541-554.

Murie K (2014). Authentic science learning contexts. In: The Language of Science Education, ed. WF McComas, Rotterdam, Netherlands: Sense Publishers.

Peffer ME, Beckler ML, Schunn C, Renken M, Revak A (2015). Science classroom inquiry ( $\mathrm{SCl}$ ) simulations: a novel method to scaffold science learning. PLOS ONE 10, e0120638; doi:10.1371/journal.pone.0120638.

Radinsky J, Bouillion L, Lento EM, Gomez LM (2001). Mutual benefit partnership: a curricular design for authenticity. J Curric Stud 33, 405-430.

Rahm J, Miller HC, Hartley L, Moore JC (2003). The value of an emergent notion of authenticity: examples from two student/teacher-scientist partnership programs. J Res Sci Teach 40, 737-756.

Rivera Maulucci MS, Brown BA, Grey ST, Sullivan S (2014). Urban middle school students' reflections on authentic science inquiry. J Res Sci Teach 51, 1119-1149

Roth W-M (1995). Authentic School Science: Knowing and Learning in Open-Inquiry Science Laboratories, Dordrecht, Netherlands: Kluwer Academic

Roth W-M (1997). From everyday science to science education: how science and technology studies inspired curriculum design and classroom research. Sci Educ 6, 373-396.
Rowland S, Green M, Lawrie G, Myatt P, Pedwell R, Wang J, Worthy P, Zimbardi $K$ (2014). The ALURE of massified undergraduate research Australian Biochem 45, 15-19

Rowland S, Pedwell R, Lawrie G, Worthy P (2016). Developing and Resourcing Academics to Help Students Conduct and Communicate Undergraduate Research on a Large Scale, Sydney, Australia: Office for Learning and Teaching.

Rowland SL, Lawrie GA, Behrendorff JBYH, Gillam EMJ (2012). Is the undergraduate research experience (URE) always best? The power of choice in a bifurcated practical stream for a large introductory biochemistry class. Biochem Mol Biol Educ 40, 46-62.

Sadler TD, McKinney L (2010). Scientific research for undergraduate students: a review of the literature. J Coll Sci Teach 39, 43.

Schwartz RS, Lederman NG, Crawford BA (2004). Developing views of nature of science in an authentic context: an explicit approach to bridging the gap between nature of science and scientific inquiry. Sci Educ 88, 610645.

Spell RM, Guinan JA, Miller KR, Beck CW (2014). Redefining authentic research experiences in introductory biology laboratories and barriers to their implementation. CBE Life Sci Educ 13, 102-110.

Squires D (1999). Educational Software and Learning: Subversive Use and Volatile Design. Proceedings of the 32nd Hawaii International Conference on System Sciences, 1999

Sundberg MD, Armstrong JE, Wischusen EW (2005). A reappraisal of the status of introductory biology laboratory education in US colleges \& universities. Am Biol Teach 67, 525-529.

Thiry H, Laursen SL, Hunter A-B (2011). What experiences help students become scientists? A comparative study of research and other sources of personal and professional gains for STEM undergraduates. J High Educ 82, 357-388.

Weaver GC, Russell CB, Wink DJ (2008). Inquiry-based and research-based laboratory pedagogies in undergraduate science. Nat Chem Biol 4, 577580 .

Winkelmann K, Baloga M, Marcinkowski T, Giannoulis C, Anquandah G, Cohen P (2014). Improving students' inquiry skills and self-efficacy through research-inspired modules in the general chemistry laboratory. J Chem Educ 92, 247-255.

Wood L, McComas WF (2014). Inquiry instruction. In: The Language of Science Education, ed. WF McComas, Rotterdam, Netherlands: Sense Publishers.

Young MF (1993). Instructional design for situated learning. Educ Technol Res Dev 41, 43-58. 